\title{
PENGARUH LATIHAN BASIC LIFE SUPPORT TERHADAP PENGETAHUAN DAN KETERAMPILAN TIM MUHAMMADIYAH DISASTER MANAGEMENT (MDMC) BANYUMAS
}

\author{
Endiyono $^{1}$, Rachmat Dwi Prasetyo ${ }^{2}$ \\ Fakultas Ilmu Kesehatan Universitas Muhammadiyah Purwokerto ${ }^{1,2}$ \\ Email : endiyono@ump.ac.id
}

\begin{abstract}
According to the World Health Organization (WHO) heart attack is the number one cause of death in developed and developing countries by contributing $60 \%$ of all deaths, occurring both outside hospitals and inside hospitals. It is estimated that around 350,000 people die per year due to cardiac arrest in America. In Indonesia, exact data or documentation of cardiac arrest events in daily life or outside the hospital has not been well documented. To maintain survival, especially if sudden cardiac arrest must be carried out basic life support (BLS). The purpose of this study is to determine the effect of basic life support training on knowledge and skills of the MDMC Banyumas Team. This study used quantitative pre experimental method with one group pre-post test design. The sampling technique uses total sampling technique with a number of samples of 30 respondents. Data collection techniques using paired t-test. The average value of knowledge obtained by respondents before being given training is $4.87 \pm 2.129$ and the average value of knowledge after training is $7.33 \pm 2.090$. The average value of skills obtained by respondents before being given training is $2.83 \pm 0.950$ and the average value of skills after being given training is $4.70 \pm 0.466$. The results of the Wilcoxon Signed Rank Test on the knowledge variable obtained a value of $Z$ of $-3,326$ with $p$ value $=0,0001$ and in the skill variable obtained an $Z$ value of $-4,684$ with p value 0,0001. There is the influence of basic life support training on the knowledge and skills of the MDMC Banyumas Team.
\end{abstract}

Keywords : Basic Life Support, training and skills.

\section{PENDAHULUAN}

Data World Health Organization (WHO) menyebutkan bahwa serangan jantung merupakan penyebab kematian nomor satu di negara maju dan berkembang dengan menyumbang $60 \%$ dari seluruh kematian, terjadi baik di luar rumah sakit maupun di dalam rumah sakit (Pusbankes 118, 2013). Diperkirakan sekitar 350.000 orang meninggal per tahunnya akibat henti jantung di Amerika dan Kanada (AHA, 2010). Di Indonesia data pasti atau pendokumentasian kejadian henti jantung di kehidupan sehari-hari atau di luar rumah sakit belum terdokumentasi dengan baik.

Manifestasi komplikasi penyakit jantung yang paling sering diketahui dan bersifat fatal adalah kejadian henti jantung mendadak. Sampai saat ini, kejadian 
henti jantung mendadak merupakan penyebab kematian tertinggi di Amerika dengan angka kejadian 330.000 orang yang meninggal karena penyakit jantung. Di Indonesia sendiri, berdasarkan hasil Riset Kesehatan Dasar (Riskesdas) tahun 2007, hanya disebutkan prevalensi nasional penyakit jantung sebesar 7,2 \%, namun angka kejadian henti jantung mendadak belum didapatkan.

Untuk mempertahankan kelangsungan hidup, terutama jika henti jantung mendadak tersebut disaksikan, harus secepatnya di lakukan tindakan basic life support (BLS) atau bantuan hidup dasar. Berdasarkan penelitian BLS akan memberikan hasil yang baik jika dilakukan dalam waktu 5 menit pertama saat korban mengalami henti jantung dan henti nafas. Tindakan bantuan hidup dasar secara definisi merupakan layanan yang dilakukan terhadap korban yang mengancam jiwa sampai korban tersebut mendapat pelayanan kesehatan yang paripurna.

Tindakan bantuan hidup dasar umumnya dilakukan oleh paramedic, namun di negara maju seperti Amerika, Kanada serta Inggris dapat dilakukan oleh orang awam yang pernah mendapatkan pelatihan sebelumnya. Keberhasilan pertolongan yang dilakukan, ditentukan oleh kecepatan dalam memberikan tindakan awal bantuan hidup jantung dasar, membuat para ahli berpikir bagaimana cara untuk melakukan suatu tindakan bantuan hidup dasar yang efektif serta melatih sebanyak mungkin orang awam dalam hal ini siswa sekolah untuk melakukan tindakan tersebut secara baik dan benar.

Berdasarkan data statistic di Amerika Serikat didapatkan 330.000 penderita yang menginggal akibat penyakit jantung, 250.000 diantaranya terjadi di luar rumah sakit. Sehingga pada praktek sehari-hari di perlukan orang awam yang dapat melakukan pelayanan bantuan hidup dasar di masyarakat sebelum mendapat pelayanan bantuan hidup lebih lanjut. Untuk menjaga mutu pada pelaksanaan bantuan pada orang awam sudah pasti diperlukan satu pelatihan bantuan hidup dasar yang terintegrasi dan komprehensif.

Kondisi kegawatdaruratan dapat terjadi dimana saja, kapan saja dan dapat menimpa siapa saja. Sudah menjadi tugas petugas kesehatan untuk menangani masalah tersebut, walaupun begitu, tidak menutup kemungkinan kondisi kegawatdaruratan dapat terjadi pada daerah yang sulit dijangkau petugas kesehatan, maka pada kondisi tersebut, peran serta masyarakat untuk membantu korban sebelum ditemukan oleh petugas kesehatan menjadi sangat penting (Sudiharto \& Sartono, 2011).

Adanya tim SAR yang terlibat dalam penanganan serta meminimalisir korban bencana alam wajib memiliki kemampuan dalam menguasai keterampilan untuk memberikan tindakan pertolongan pertama Basic Life Support serta mengenal keadaan gawat darurat akibat trauma maupun non trauma yang sering dijumpai pada korban bencana. Seorang penolong harus memiliki pengetahuan serta pelatihan dalam melakukan tindakan pertolongan pada korban bencana, salahsatunya yaitu Basic Life Support. Pengetahuan tentang BLS merupakan hal yang 
penting dalam dasar keterampilan yang harus dimiliki oleh tim SAR sebagai relawan korban bencana dalam menolong dan memberikan penanganan pertama untuk mempertahankan kehidupan saat kondisi kegawatdaruratan sebelum di tangani oleh petugas kesehatan.

Bantuan hidup dasar atau Basic Life Support merupakan usaha yang pertama kali dilakukan untuk mempertahankan kehidupan saat penderita mengalami keadaan yang mengancam nyawa (Guyton \& Hall, 2008). Bantuan hidup dasar merupakan salah satu upaya yang harus segera dilakukan oleh seorang apabila menemukan korban yang membutuhkannya. Keterampilan BHD menjadi penting karena didalamnya diajarkan tentang bagaimana teknik dasar penyelamatan korban dari berbagai kecelakaan atau musibah sehari-hari yang biasa dijumpai (Fajarwati, dalam Hasanah, 2015).

Berdasarkan latar belakang diatas, Peneliti tertarik untuk melakukan penelitian dengan judul "Pengaruh Pelatihan Basic Life Support Terhadap Pengetahuan dan Keterampilan TIM MDMC Banyumas".

\section{METODE PENELITIAN}

Penelitian ini adalah penelitian kuantitatif, penelitian ini bertujuan untuk menilai pengaruh pemberian Pelatihan Basic Life Support Terhadap Pengetahuan dan Keterampilan TIM MDMC Banyumas. Jenis penelitian yang akan digunakan dalam penelitian ini adalah dengan menggunakan metode pre experimental dengan design rancangan penelitian ini menggunakan one group pre-post test design. Sampel dalam penelitian ini sebanyak 30 responden. Analisis data yang digunakan dalam penelitian ini adalah uji Wilcoxon. Instrument yang digunakan dalam penelitian ini adalah kuisioner untuk mengetahui sejauh mana tingkat pengetahuan, dimana kuisioner ini telah dilakukan uji validitas dan realibilitas. Untuk instrument keterampilan menggunakan lembar observasi bantuan hidup dasar dari Yayasan Ambulans Gawar Darurat 118 Jakarta.

Tabel 1. Data Demografi

\section{HASIL PENELITIAN}

\begin{tabular}{lcc}
\hline Karakteristik & Frekuensi & \% \\
\hline Jenis kelamin & 19 & 63.3 \\
Laki laki & 11 & 37.7 \\
Perempuan & & \\
Usia (tahun) & 18 & 60.0 \\
$15-25$ & 6 & 20.0 \\
$26-30$ & 6 & 20.0 \\
$36-45$ & & \\
Pendidikan terakhir & 24 & 80.0 \\
SMA & 2 & 6.7 \\
D3 & & \\
\hline
\end{tabular}




\begin{tabular}{lcc}
\hline S1 & 3 & 10.0 \\
S2 & 1 & 3.3 \\
Keikutsertaan dalam BLS & & \\
Ya & 8 & 26.7 \\
Tidak & 22 & 73.3 \\
\hline
\end{tabular}

Tabel 2. Pengaruh Pelatihan Basic life support Terhadap Pengetahuan TIM SAR MDMC Banyumas tentang Basic Life Support.

\begin{tabular}{lllll}
\hline & N & Mean & Nilai Z & $p$ \\
\hline Pengetahuan sebelum & 30 & $4,87 \pm 2,129$ & \multirow{2}{*}{0.326} & 0,0001 \\
Penegtahuan sesudah & 30 & $7,33 \pm 2,090$ & & \\
\hline
\end{tabular}

Berdasarkan hasil penelitian diatas, bahwa nilai rata-rata pengetahuan responden sebelum pelatihan sebesar $4,87 \pm 2,129$ dan sesudah pelatihan nilai ratarata meningkat menjadi 7,33 $\pm 2,090$. Hasil analisis bivariat dengan menggunakan uji Wilcoxon, diperoleh nilai $Z$ sebesar -3,326 dan nilai significancy sebesar 0,0001 ( $\mathrm{p}<0,05)$. Hasil uji statistik ini dapat disimpulkan bahwa ada pengaruh pelatihan basic life support terhadap pengetahuan TIM MDMC Banyumas tentang Basic Life Support.

Tabel 3. Pengaruh Pelatihan Basic life support Terhadap Keterampilan TIM MDMC Banyumas tentang Basic Life Support.

\begin{tabular}{lllll}
\hline & $\mathrm{N}$ & Mean & Nilai Z & $p$ \\
\hline Keterampilan sebelum & 30 & 2,83 & & \\
& & $\pm 0,950$ & $-4,684$ & 0,0001 \\
Keterampilan sesudah & 30 & 4,70 & & \\
& & $\pm 0,466$ & & \\
\hline
\end{tabular}

Berdasarkan hasil penelitian diatas, bahwa nilai rata-rata ketrampilan responden sebelum pelatihan sebesar $2,83 \pm 0,950$ dan sesudah pelatihan nilai ratarata meningkat menjadi 4,70 $\pm 0,466$ Hasil analisis bivariat dengan menggunakan uji Wilcoxon, diperoleh nilai Z sebesar -4,684 dan nilai significancy sebesar 0,0001 (p $<0,05)$. Hasil uji statistik ini dapat disimpulkan bahwa ada pengaruh pelatihan basic life support terhadap keterampilan TIM MDMC Banyumas tentang Basic Life Support.

Hasil penelitian menunjukan bahwa nilai rata-rata pengetahuan responden sebelum pelatihan sebesar 4,87 $\pm 2,129$ dan sesudah pelatihan nilai rata-rata meningkat menjadi 7,33 $\pm 2,090$. Hasil analisis bivariat dengan menggunakan uji Wilcoxon, diperoleh nilai Z sebesar -3,326 dan nilai significancy sebesar 0,0001 ( $\mathrm{p}$ $<0,05)$. Hasil uji statistik ini dapat disimpulkan bahwa ada pengaruh pelatihan basic life support terhadap pengetahuan TIM MDMC Banyumas tentangbasic life 
support. Karena telah terjadi peningkatan dari 4,87 menjadi 7,33 point (peningkatan sebesar 2,46 point).

Hasil penelitian ini didukung oleh Pratiwi (2016), menunjukkan ada hubungan yang signifikan antara pelatihan dengan pengetahuan siswa sekolah menengah atas dengan nilai p-value sebesar $0,001<0.05$ ). Hal ini menunjukkan manfaat positif dari pelatihan BLS. Mayoritas responden menunjukkan peningkatan pengetahuan saat post-test. Hal ini mungkin karena keinginan dan semangat untuk belajar dari responden.

Notoadmodjo (2010), mengatakan pengetahuan (knowledge) adalah hasil tahu dari manusia dan ini terjadi setelah orang mengadakan penginderaan terhadap suatu objek tertentu. Dan beliau juga menjelaskan bahwa semakin tinggi tingkat pengetahuan seseorang, maka semakin tinggi pula seseorang memahami pentingnya melakukan kegiatan untuk mencapai tujuan.

Pengembangan suatu pengetahuan terlihat dari kemampuan seseorang mampu mengaplikasikannya salah satunya dalam bentuk keterampilan. Menurut Ningrum (2007), proses pengembangan keterampilan dapat dilakukan setelah kegiatan pembelajaran tindak lanjut dari kegiatan pembelajaran. Pengembangan keterampilan harus dimulai dari apa yang dikuasai siswa ke keterampilan yang belum dikuasainya.

Hal ini sesuai dengan teori yang dikemukakan oleh Cristian (2008) bahwa pengetahuan yang baik sangat berpengaruh pada kemampuan yang baik pula, kemampuan seseorang menerapkan pengetahuan yang dimiliki kedalam bentuk tindakan dimana tim SAR harus memiliki keterampilan baik dalam komunikasi efektif, objektifitas dan kemampuan dalam membuat keputusan klinis secara tepat dan tepat agar perawatan setiap pasien menjadi maksimal.

Hasil peneltiian ini sesuai dengan Lontoh (2013), yang mengatakan bahwa ada pengaruh pelatihan teori BHD terhadap pengetahuan resusitasi jantung paru siswa-siswi SMA Negeri 1 Toili.

Hasil penelitian ini menunjukkan bahwa tenaga penyelamat sebagai orang yang pertama kali menemukan korban dapat melakukan pertolongan pertama pada siapapun dalam keadaan yang gawat darurat terutama pada orang yang mengalami henti jantung dan henti nafas yang merupakan indikasi dari pemberian BHD. Pelatihan tentang Bantuan Hidup Dasar (BHD) dapat meningkatkan pengetahuan tenaga penyelamat tentang BHD dan sangat menunjang untuk meningkatkan pengetahuan apabila dilakukan secara berkala.

Hasil penelitian menunjukan bahwa nilai rata-rata ketrampilan responden sebelum pelatihan sebesar $2,83 \pm 0,950$ dan sesudah pelatihan nilai rata-rata meningkat menjadi 4,70 $\pm 0,466$ Hasil analisis bivariat dengan menggunakan uji Wilcoxon, diperoleh nilai $\mathrm{Z}$ sebesar $-4,684$ dan nilai significancy sebesar 0,0001 (p $<0,05)$. Hasil uji statistik ini dapat disimpulkan bahwa ada pengaruh pelatihan 
basic life support terhadap ketrampilan TIM SAR MDMC Banyumas tentang basic life support. Karena telah terjadi peningkatan dari 2,83 menjadi 4,70 point (peningkatan sebesar 1,47 point)

Hasil penelitian ini sejalan dengan Turambi (2016), yang menyatakan ada pengaruh pelatihan bantuan hidup dasar terhadap peningkatan ketrampilan siswa dengan nilai $\mathrm{p}=0,000<0,05$. Hal ini menunjukkan bahwa pelatihan bantuan hidup dasar memberi hasil yang bermakna.

Menurut Pirton \& Nazmudin, (2015), Bantuan Hidup Dasar (BHD) merupakan usaha sederhana yang dilakukan untuk mengatasi keadaan yang mengancam nyawa seseorang sehingga dapat mempertahankan hidupnya untuk sementara. Bantuan Hidup Dasar dilakukan sampai bantuan atau pertolongan lanjutan datang. Bantuan hidup dasar merupakan bagian dari pengelolaan gawat darurat medik yang bertujuan untuk mencegah berhentinya sirkulasi atau berhentinya respirasi (Frame, 2010). Keadaan para korban kecelakaan dapat semakin buruk atau berujung pada kematian jika tidak ditangani dengan cepat (Sunyoto, 2010). Bantuan Hidup Dasar dapat diartikan sebagai usaha yang dilakukan untuk mempertahankan kehidupan seseorang yang sedang terancam jiwanya (Frame, 2010). Frame juga menyatakan bahwa Bantuan Hidup Dasar harus diberikan pada korban yang mengalami henti nafas, henti jantung, dan perdarahan. Ketrampilan seseorang agar dapat memberikan BHD dengan baik harus melalui pelatihan.

Pelaksanaan keterampilan seseorang harus mempunyai dasar yang telah didapat baik berupa informasi ataupun berupa pelatihan. Pengembangan keterampilan harus dimulai dari apa yang dikuasai seseorang, keterampilan yang belum dikuasainya. Hal ini menyatakan bahwa pelatihan menjadi lebih efektif untuk meningkatkan keterampilan yang sesungguhnya, hal ini tidak lepas dari pemberian pelatihan. Proses pengembangan keterampilan dapat dilakukan setelah kegiatan pembelajaran, tindaklanjut dan pengembangan suatu pengetahuan yang terlihat dari kemampuan seseorang mampu mengaplikasikannya, salah satunya dalam bentuk keterampilan (Ningrum 2007).

Faktor-faktor yang dapat mempengaruhi keterampilan menurut Bertnus (2009) yaitu pengetahuan, pengalaman, keinginan/motivasi. Seorangtim SAR harus memiliki faktor-faktor tertentu yang dapat mempengaruhi keterampilan, hal ini berkaitan dengan tindakan-tindakan yang harus dilakukan untuk membangun suatu keterampilan yang baik. Tim SAR harus memiliki keterampilan yang profesional, keterampilan (kompetensi) khusus tersebut bisa didapatkan melalui pendidikan dan pelatihan tentang kegawatdaruratan. Keterampilan tersebut harus selalu ditingkatkan atau dikembangkan dan dipelihara sehingga menjamin perawat dapat melaksanakan peran dan fungsinya secara professional (Musliha, 2010).

Hasil penelitian yang dilakukan oleh Chaundary, Parikh, dan Dave (2011) yang menjelaskan bahwa terjadi peningkatan keterampilan RJP dapat dilakukan 
dengan cara mengikuti pelatihan BHD. Pelatihan yang berkesinambungan diperlukan untuk menyegarkan kembali pengetahuan dan keterampilan. Keenan, Lamacraft, dan Joubert (2009), menjelaskan bahwa penyegaran pelatihan harus dilakukan setiap 6-12 bulan untuk mempertahankan kemampuan skill BHD, hal ini disebabkan karena keterampilan tim SAR tentang BHD khususnya RJP dapat menurun setelah 2 minggu dilakukan pelatihan.

Frame (2010), menyatakan bahwa bantuanhidup dasar (BHD) dapat diajarkan kepada siapa saja. Setiap orang dewasa seharusnya memiliki keterampilan BHD, bahkan anak-anak juga dapat diajarkan sesuai dengan kapasitasnya, baik tenaga kesehatan maupun bukan tenaga kesehatan seharusnya diajarkan tentang bantuan hidup dasar agar dapat memberikan pertolongan keselamatan dengan segera.

\section{KESIMPULAN}

Berdasarkan hasil dan pembahasan pada penelitian tentang "Pengaruh Pelatihan Basic Life Support Terhadap Pengetahuan dan Keterampilan TIM MDMC Banyumas tentang basic life support", maka dapat disimpulkan sebagai berikut:

1. Terdapat pengaruh pelatihan dengan metode ceramah dan tanya jawab Basic Life Support terhadap pengetahuan TIM MDMC Banyumas tentang basic life support.

2. Terdapat pengaruh pelatihan dengan metode praktek langsung Basic Life Support terhadap keterampilan TIM MDMC Banyumas tentang basic life support

Dari hasil penelitian ini, disarankan supaya :

1. Hasil penelitian ini diharapkan bagi tim MDMC Banyumas harus mengetahui, memahami, tentang BLS dan mampu mengaplikasikan hasil pengetahuannya tentang Basic Life Support (BLS) sehingga bila mendapat korban atau pasien dengan kegawatdaruratan dapat segera tertangani.

2. Bagi peneliti selanjutnya agar menggunakan metode pelatihan lain seperti small group discussion atau peer group serta menggunakan media lain yang lebih menarik seperti audio visual dan lainnya, menambah variabel penelitian dalam aspek perilaku atau aspek lain dengan metode pengumpulan data menggunakan instrumen lain seperti teknik wawancara dan lain-lain.

\section{DAFTAR PUSTAKA}

Bertnus. (2009). Faktor yang Mempengaruhi Keterampilan. diakses pada tanggal 10 Juni 2018 dari http://digilib.unimus.ac,id/files/disk1/115/ 
Chaudhary, A., Parikh, H., \& Dave, V. (2011). Current scenario:Knowledge of basic life support in medical college. National Journal of Medical Research, $1(2)$,

Frame. (2010). PHTLS: basic and advanced prehospital trauma life support. Jakarta: EGC

Keenan, M. Lamacraft, G., \& Joubert, G. (2009). A Survey Of Nurse Basic Life Support knowledge and training at a tertiary hospital. African Journal Of Health proffesions Education, 1(1)

Lontoh, C. (2013). Pengaruh Pelatihan Teori Bantuan Hidup Dasar Terhadap Pengetahuan Resusitasi Jantung Paru Siswa-Siswi SMA Negeri 1 Toili. Skripsi. Manado: Program Studi Ilmu Keperawatan Fakultas Kedokteran Universitas Sam Ratulangi Manado

Musliha (2010). Keperawatan Gawat Darurat. Yogyakarta: Nuha Medikal

Notoatmodjo. (2010). Metode Penelitian Kesehatan. Jakarta : Rineka Cipta. . (2007). Promosi Kesehatan dan Ilmu Perilaku. Jakarta: Rineka Cipta.

Nursalam. (2011). Konsep dan Penerapan Metodologi Penelitian Ilmu Keperawatan . Jakarta: Salemba Medika.

Pratiwi. (2016). Basic Life Support: Pengetahuan Dasar Siswa Sekolah Menengah Atas. 7(2) diakses pada tanggal 10 Juni 2018 dari http://ejournal.umm.ac.id/index.php/keperawatan/issue/view

Sudiharto. (2014). Basic Trauma Cardiac Life Support (BTCLS) in Disaster. Jakarta: Sagung Seto.

Sunyoto.(2010, agustus 3). Presentasi Case Study, Simulasi. Maret 29, 2012.http://fkm.unsri.ac.id/index. php?option=com_content\&view= article \&id=44:presentasicasestudy-simulasi\&catid=8:informasi

Turambi. (2016). Pengaruh Pelatihan Bantuan Hidup Dasar (BHD) Terhadap Peningkatan Pengetahuan dan Keterampilan Siswa kelas XI Dan XII SMA Negeri 2 Langowan. Buletin Sariputra 6 (2)

WHO, 2010. Mortality, road traffic deaths. Desember 29, 2017. http://apps. who.int/ghodata/?vid=5120 